\title{
Natural Disasters Versus Anthropogenic Activities in Nepal Himalayas: Case Study from Ghatte Khola, Myagdi
}

\author{
Narayan Gurung \\ Kadoorie Agricultural Aid Association, Pokhara, Nepal \\ Doctoral student, Université Paris Diderot, UMR 8586 PRODIG, 75205 Paris Cedex 13, France \\ E-mail:jyonus@hotmail.com
}

\begin{abstract}
In the Himalayas, geo-hazards are natural events occurring more or less frequently and of a greater or lesser magnitude. But when natural hazards affect people and property, then it becomes disasters. It's believed that natural disasters as such do not exist. Everything is just natural hazard and anything can turn into disasters due to anthropogenic activities. Thus, natural phenomenons are hazards while disasters are anthropogenic. In this regard, a case study was being conducted in the Ghatte Khola (Dana) of Myagdi District in Western Central Nepal, where in a context of growing population and haphazard construction of infrastructures, natural dynamics have turned into disasters. The Ghatte Khola is an intermittent, right bank tributary of the Kali Gandaki, which behaves occasionally as a debris flow, in relation with slope instabilities that affect its upstream catchment. The debris flows are usually triggered during heavy cloudbursts, and can cause damages and losses downstream, along the wide alluvial fan built at the tributary junction and upon which Dana village (Myagdi District) is settled. Inhabitants are aware of this ephemeral, yet threatening behaviour of the stream that may also affect the Kali Gandaki valley upstream from the confluence (Lat. 28 32 '22" $\mathrm{N}$ and Long. 8339'03" E). The Ghatte Khola is often affected by debris flows bringing sediment fluxes that are eroding its banks every year. A motor bridge was being built over Ghatte Khola near the confluence with Kali Gandaki and further, a large electric power station is being built on the right bank of Ghatte Khola. Sadly, the bridge was washed away by the flash flood in Ghattekhola on $25^{\text {th }}$ May 2019. This study was focused on vulnerability of these man made infrastructures and their future on Ghatte Khola debris flow dynamics, with hazard that might occasionally transform into disaster.
\end{abstract}

Keywords: Ghatte Khola, Natural disaster, Motor bridge

1. Introduction

Since the last 20 years, road construction in Nepal has increased rapidly, in most cases with poor consideration of hazards (rockfall, landslides, Volume 1 Issue 1 debris flow) that may affect them. Currently, national road construction is fostered by China's Belt and Road Initiative (Silk Road annexes), as it is proven by the under construction 2 lane 
black-top "Kali Gandaki (KG) corridor". Yet, the dynamics of the KG tributary catchments prone to debris flows are rarely considered by engineers despite it represents a common threat to the main road. It was focused on the Ghatte Khola (Myagdi District) and tried to assess the relevance of its bridge under construction.

\section{Methodology}

Disasters are supposed to be due to risk-blind development. What makes hazards become disasters depends primarily on the way societies develop, build and construct. Road construction is an unavoidable step in the infrastructure development of Nepal. Yet, it is often considered as one of the causes of the extent of landslides. Hence, considering the hill sloperiver connectivity is a priority. The study was a part of a scientific research which would be useful for the people of Nepal and for its future development.

Detailed hydrological studies were carried out at the proposed bridge site in order to check the suitability of the bridge over the Ghattekhola, Myagdi. This study covered the following aspects.

- Catchment area of the river up to the bridge site.

- Cross sections at proposed bridge site, at about $500 \mathrm{~m} \mathrm{u} / \mathrm{s}$ and about $200 \mathrm{~m} \mathrm{~d} / \mathrm{s}$, and silt factor at bridge site.

- Bed slope of the river which states from $100 \mathrm{~m} \mathrm{u} / \mathrm{s}$ and end at $100 \mathrm{~m} \mathrm{~d} / \mathrm{s}$ of the bridge site.

- Maximum discharge calculated by established formulae with different return periods.

- Velocity and depth of flow at the time of survey.

- Shifting of the river in the past at proposed site and in vicinity of it.

- Necessary information required for river control design, construction and/or maintenance of the bridge.

During this study the methods included geomorphic mapping, description and analysis of natural sections (across slopes, along river sides, etc.) including computation of peak flows. A multi decadal perspective has been proposed as its future investigation using old satellite images (Landsat from 1977) together with the most recent ones, in addition with available series of repeated photographs of the same sites, so that temporal map of change will be produced. This study also included interviews with elderly local people in order to know their knowledge about past hazard, river dynamics and to hear the changes in landscape due to the construction of infrastructure projects.

For comparison of cross sections along Ghattekhola, corresponding cross sections were measured in six places as depicted in the Figure 3 . These were measured before and after the flash flood on $25^{\text {th }}$ May, 2019. A flash flood had occurred at $3.40 \mathrm{pm}$ on $25^{\text {th }}$ May, 2019 that washed away the under construction motor bridge over Ghatte Khola. The cross sections were measured first on $2^{\text {nd }}$ March, 2019 and these were re-measured on $15^{\text {th }}$ June to check how these were changed after the flash flooding on $25^{\text {th }}$ May. These could be seen in Figure 4 - 9 for the comparison of temporal changes. 
The river gradient was about $13 \%$ as measured on $15^{\text {th }}$ June. The longitudinal section was measured and has been depicted in Figure 10.

\section{Results and Discussions}

\subsection{Flood from Empirical Formulae}

The flood discharge at bridge site was calculated for different return period using various empirical formulae, as shown in table below.

The flood discharge at the bridge site was determined by using following indirect method.

- DHM/ WECS Method (Hydest)

- Rational Method

\subsubsection{WECS Method}

Water and Energy Commission (1990) issued a report of task force, which developed the methodology for estimating the peak flow of the un-gauged catchments of Nepal. The regression equations that have been proposed to estimate instantaneous flood of 2 years and 100 years return periods by WECS have been modified by Sharma and Adhikari (2004) based on long term data. They proposed the following equations for instantaneous peak flow estimation.

For 2 year return period:

$\mathrm{Q}_{2}=2.29 * \mathrm{~A}^{0.86}$

For 100 year return period

$\mathrm{Q}_{100}=20.7 * \mathrm{~A}^{0.72}$

Where $\mathrm{Q}$ is the discharge in $\mathrm{m}^{3} / \mathrm{s}$ and $\mathrm{A}$ is the area in $\mathrm{km}^{2}$.
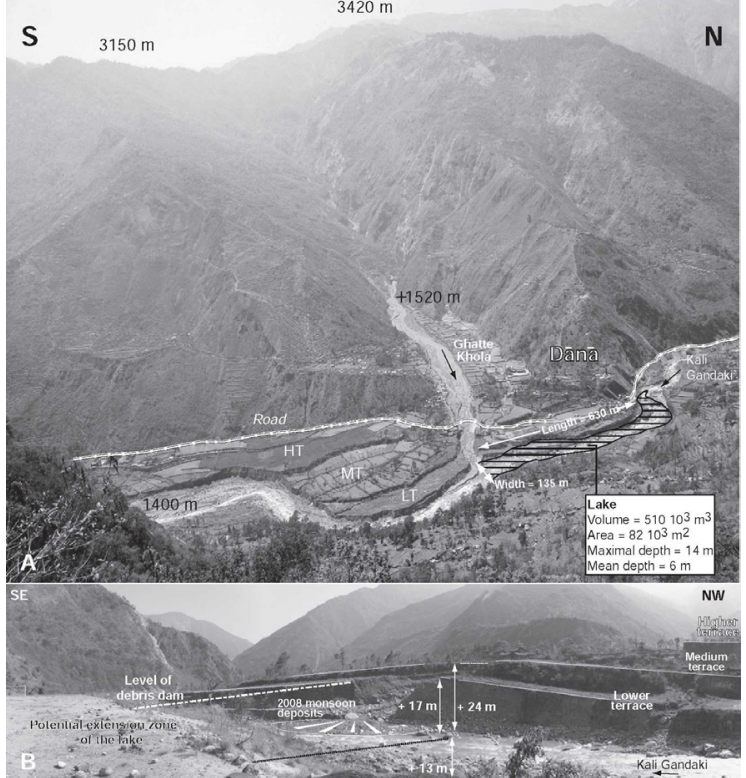

Figure 1

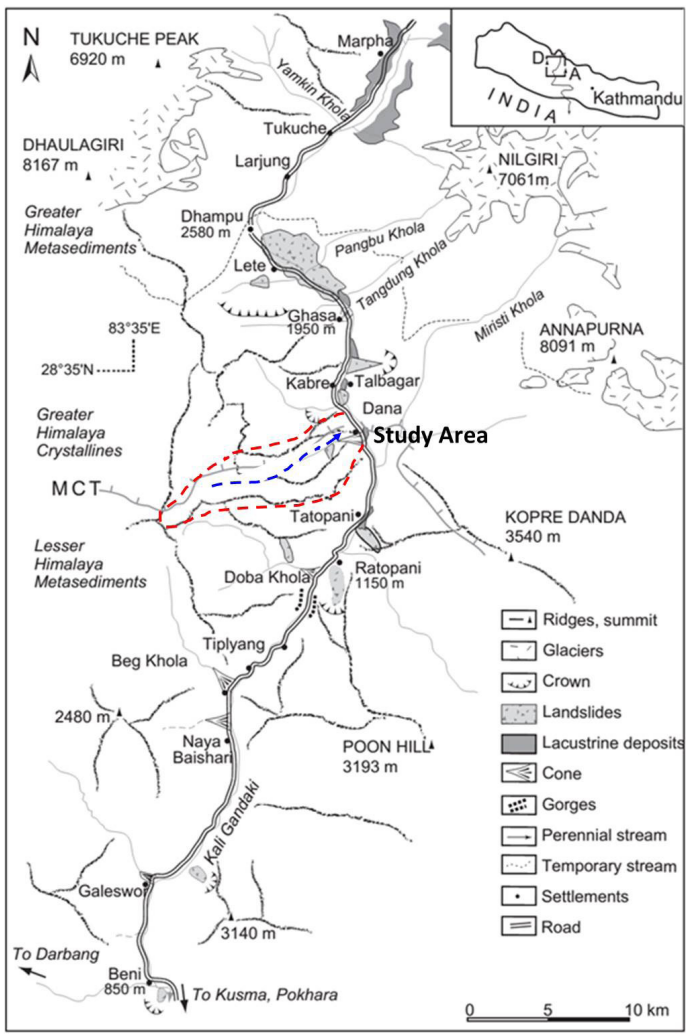

Figure 2

Figure 1: The Confluence of the Ghatte Khola 
with the Kali Gandaki River. A: The alluvial fan of the Ghatte Khola is the progradation of the Kali Gandaki river flood plain. B: The Ghatte Khola channel is sporadically affected by debris-flow events that are now threatening the newly built road and bridge. Photo by M. Fort. Figure 2: Kali Gandaki Valley Showing Study Area.

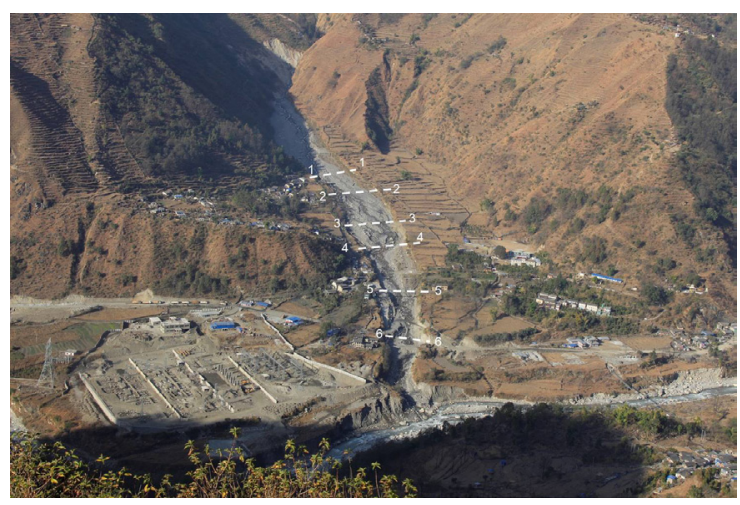

Figure 3

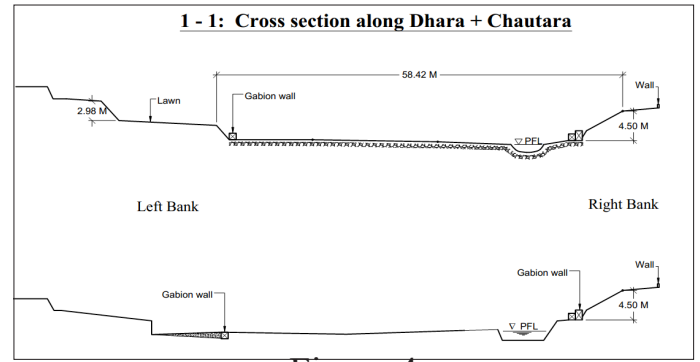

Figure 4

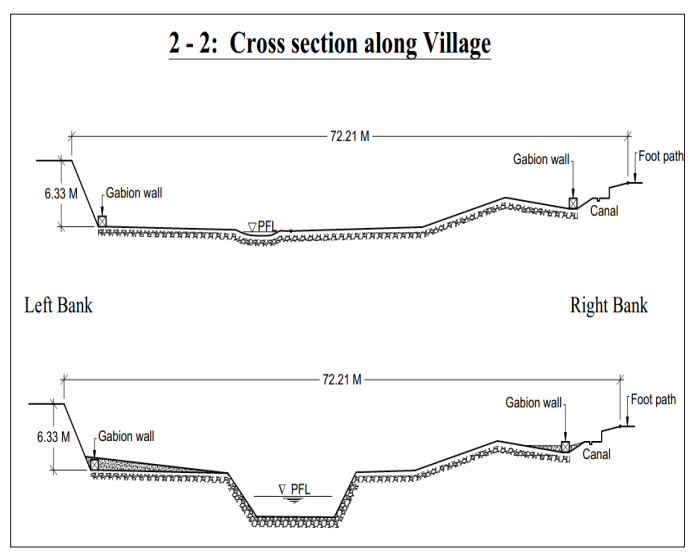

Figure 5

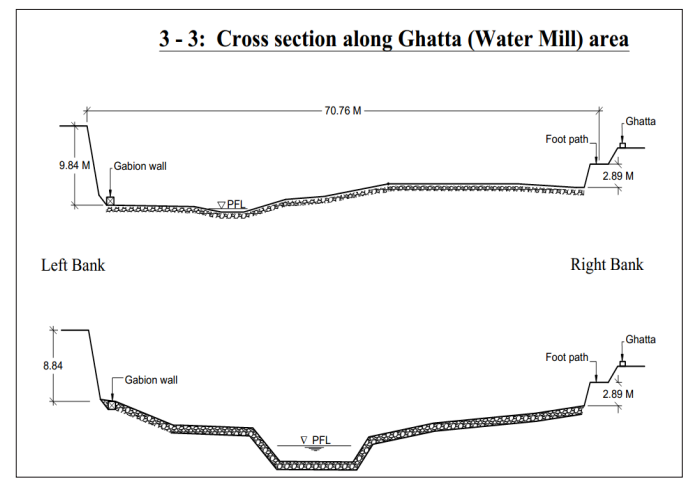

Figure 6

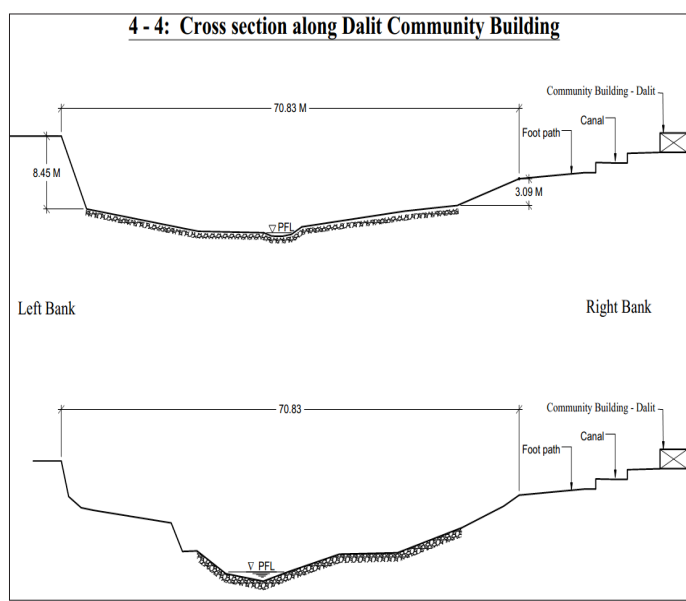

Figure 7

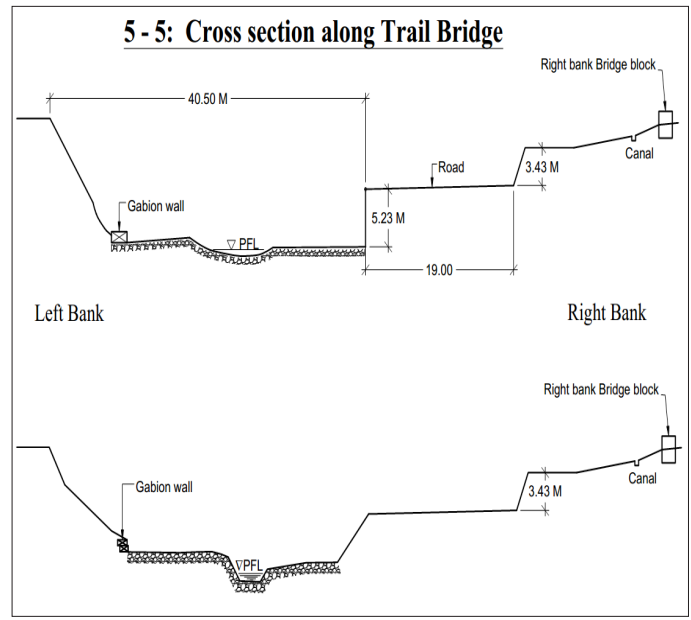

Figure 8 


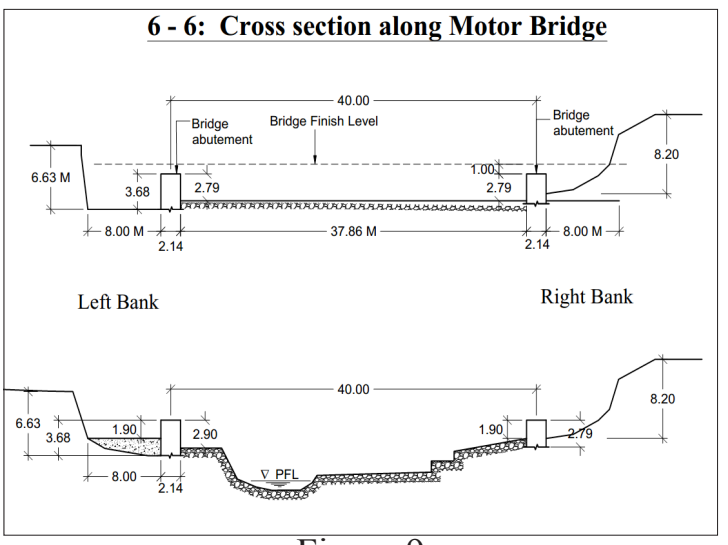

Figure 9

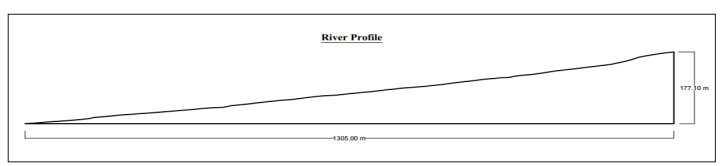

Figure 10

Similarly, for $\mathrm{Q}_{5}, \mathrm{Q}_{10}$ and $\mathrm{Q}_{50}$, following logarithmic formulae were used.

$Q_{5}=e\left(\ln Q_{2}+0.842\left(\frac{\ln \left(\frac{Q_{100}}{Q_{2}}\right)}{2.326}\right)\right)$
$Q_{10}=e\left(\ln Q_{2}+1.282\left(\frac{\left.\ln \left(\frac{Q_{100}}{Q_{2}}\right)\right)}{2.326}\right)\right)$

Probability $=\frac{\text { Rank }}{n+1} \times 100$

$Q_{50}=e\left(\ln Q_{2}+2.054\left(\frac{\ln \left(\frac{Q_{100}}{Q_{2}}\right)}{2.326}\right)\right)$

Table 1: Instantaneous Flood Flow Statistics by

Table 3: Flood Recurrence Interval (R.I.)

\begin{tabular}{|c|c|c|c|c|c|c|}
\hline $\begin{array}{l}\text { Year } \\
\text { (A.D.) }\end{array}$ & $\begin{array}{l}\text { Peak Runoff } \\
\left(\mathrm{m}^{3} / \mathrm{s}\right)\end{array}$ & Rank & $\begin{array}{l}\text { Probability }(\%) \\
\text { Probability }=\frac{\text { Rank }}{n+1} \times 100\end{array}$ & $\begin{array}{l}\text { R.I. (Years) } \\
R . I_{.}=\frac{n+1}{\text { Rank }}\end{array}$ & $\begin{array}{l}\text { Linear Water Way }(\mathrm{m}) \\
W=4.75 \sqrt{Q}\end{array}$ & $\begin{array}{l}\text { Present clear linear } \\
\text { water way }(\mathrm{m})\end{array}$ \\
\hline 2013 & 76.46 & 5 & 71.43 & 1.40 & 41.53 & \multirow{6}{*}{37.86} \\
\hline 2014 & 95.57 & 1 & 14.29 & 7.00 & 46.44 & \\
\hline 2015 & 89.20 & 3 & 42.86 & 2.33 & 44.86 & \\
\hline 2016 & 95.57 & 1 & 14.29 & 7.00 & 46.44 & \\
\hline 2017 & 63.76 & 6 & 85.71 & 1.17 & 37.93 & \\
\hline 2018 & 86.01 & 4 & 57.14 & 1.75 & 44.05 & \\
\hline
\end{tabular}

WECS Method

Technical Journal -2019

\begin{tabular}{|l|l|}
\hline Return Period (years) & $\mathbf{Q}(\mathbf{m} 3 / \mathbf{s})$ \\
\hline 2 & 13.40 \\
\hline 5 & 26.79 \\
\hline 10 & 38.48 \\
\hline 50 & 72.62 \\
\hline 100 & 90.84 \\
\hline
\end{tabular}

\subsubsection{Rational Method}

The following formula was used for the estimation of peak flow by Rational method.

$Q=C I A$

Where, $\mathrm{Q}=$ peak flow $\left(\mathrm{ft}^{3} / \mathrm{s}\right), \mathrm{I}=$ Rainfall intensity in inch $/ \mathrm{hr}, \mathrm{A}=$ catchment area in acres. $\mathrm{A}=$ Total catchment area $=7.8 \mathrm{~km}^{2}=1926.60$ Acres

Table 2: Flow for Different Years by Rational Method

\begin{tabular}{|c|c|c|c|}
\hline $\begin{array}{l}\text { Coefficient } \\
\text { (C) }\end{array}$ & Year & $\begin{array}{l}\text { Rainfall } \\
\text { Intensity } \\
\text { (inch/hr) }\end{array}$ & $\mathbf{Q}\left(\mathrm{m}^{3} / \mathrm{s}\right)$ \\
\hline 0.3 & 2013 & 4.72 & 76.46 \\
\hline 0.3 & 2014 & 5.91 & 95.57 \\
\hline 0.3 & 2015 & 5.51 & 89.20 \\
\hline 0.3 & 2016 & 5.91 & 95.57 \\
\hline 0.3 & 2017 & 3.94 & 63.76 \\
\hline 0.3 & 2018 & 5.31 & 86.01 \\
\hline
\end{tabular}




\section{Conclusion}

Two methods (WECS Method and Rational Method), commonly used in Nepal, were applied for estimating the discharge. The modelling results were $72.62 \mathrm{~m} 3$ by WECS and 63.76 to $95.57 \mathrm{~m} 3$ by Rational Method. The provided water way of the future Dana motor bridge (1) is $37.86 \mathrm{~m}$ while it showed the requirement of at least $41 \mathrm{~m}$ water way to safely pass that much of discharge through the bridge meaning that, the future bridge is supposed to be at significant threat of high flood. (2) More specifically, in the last 6 years, the bridge would have been damaged 5 times out of 6 . It is worth to be noted that the applied methods do model only floods, but the situation could be even more critical in case of landslide lake outburst floods or debris flows. In addition, a transmission towers field, and a bad control of runoff water, could show that natural dynamics might be amplified by anthropogenic perturbations and infrastructure construction.

\section{References}

Chalise, S.R. (1994). High mountain hydrology in changing climates: perspectives form the Hindukush Himalayas.

DOI (2006).Guidelines for irrigation systems design in hills and valleys, Full Bright Consultancy Pvt. Ltd. and Project Engineering Consultancy and Research Pvt. Ltd. (JV).

Fort M. (1987). Geomorphic and Hazards mapping in the dry, continental Himalaya: 1:50,000 maps of Mustang District, Nepal. Mt Res Dev 7(3):222-238
Fort M. et el. (2010). Hillslope-channel coupling in the Nepal Himalayas and threat to man-made structures: The middle Kali Gandaki valley, Elsevier, Geomorphology 124 (2010),pg 178 - 199

Garge, S.K. (2001). Irrigation Engineering and Hydraulic Structures. Khanna Publishers, Delhi.

Jacob, B.S. (1995). Hill Irrigation Engineering with special emphasis on Planning, design and implementation of farmer hill systems. IOE Pulchowk campus, TU, Kathmandu Nepal and The Ford Foundation, New Delhi, India.

Jha, P. C. (1996). Maximum storm design flood for road structures of Nepal, a Ph.D. Dissertation, Moscow.

Rijal, K.P. (2012). East Rapti River Training with PEP perspective. DWIDP bulletin, 2012, Pulchowk, Lalitpur, Nepal

Sharma, K. P, and Adhikari, N.R.(2004). Hydrological Estimations in Nepal. DHM, GON, Nepal.

Shilpakar, R.L. (2003), Geo-information procedures for water accounting: A case of the East Rapti River Basin, Nepal, an unpublished M.Sc. thesis submitted to International Institute for Geo information Science and Earth Observation, ITC, Enschede, The Netherlands.

Subramanya, K., (2004). Engineering Hydrology (Second Edition), TATA McGRAW Hill, New Delhi. 